\title{
Competição Baseada em Competências e Aprendizagem Organizacional: em Busca da Vantagem Competitiva
}

\author{
João Batista Diniz Leite \\ Melody de Campos Soares Porsse
}

\section{ResUMO}

O objetivo do presente trabalho é aprofundar a discussão da Teoria da Competição Baseada em Competências. Esta abordagem, que propõe combinar duas perspectivas da teoria estratégica (Escola de Posicionamento Estratégico e Teoria Baseada em Recursos), reconhece os níveis de incerteza que envolvem a mudança estratégica, assim como a importância dos processos de criação de conhecimento e aprendizagem organizacional. Como contribuição deste trabalho, sugere-se uma proposta pedagógica construtivista, com foco na Andragogia, para a eficácia dos processos de criação de conhecimento e da aprendizagem organizacional. Com o propósito de exemplificar essa proposta, apresentam-se dados empíricos, coletados por meio de técnicas multimétodos, de uma experiência que está sendo realizada atualmente no Banco do Brasil.

Palavras-chaves: vantagem competitiva; competências; conhecimento; aprendizagem; construtivismo.

\begin{abstract}
The objective of the present paper is to deepen the discussion of the Competencies Based on Competition Theory. This approach, which proposes to combine two traditional streams of theory of strategy (The Strategic Positioning School and the Resource-Based Theory) recognizes different levels of uncertainty which involves the strategic change, as well as knowledge creation processes and organizacional learning. As a contribution of this work, a constructivist pedagogical proposal is presented, with a focus in Andragogy, for the effectiveness of knowledge creation processes and organizational learning. With the purpose of illustration, it shows empiric data, collected by multimethod techniques, from an experience that is being accomplished now in Banco do Brasil.
\end{abstract}

Key words: competitive advantage; competencies; knowledge; learning; constructivism. 


\section{INTRODUÇÃO}

A vantagem competitiva, isto é, a ocorrência de níveis de desempenho econômico acima da média do mercado em virtude das estratégias adotadas pelas empresas, é explicada de forma diferenciada por quatro correntes do pensamento sobre estratégia empresarial, as quais estão agrupadas em dois eixos de análise, sendo cada um composto por duas correntes (Vasconcelos e Cyrino, 2000).

No primeiro eixo, localizam-se duas teorias associadas a aspectos estáticos da concorrência, fundamentadas na noção de equilíbrio econômico, ou seja, a Teoria de Posicionamento Estratégico (inspirada na Teoria da Organização Industrial) e a Teoria Baseada em Recursos. As duas teorias que compõem este primeiro eixo representam a corrente principal ou mainstream da teoria da estratégia (Heene e Sanchez, 1997). De um lado, encontra-se a Teoria de Posicionamento Estratégico, que prioriza a vantagem competitiva como resultado exógeno à organização, sendo uma questão de posicionamento, decorrente da estrutura da indústria, da dinâmica da concorrência e do mercado, orientada por uma visão de fora para dentro da organização (paradigma outside-in). De outro lado, aparece a Teoria Baseada em Recursos, a qual reconhece as especificidades das organizações, explicando a vantagem competitiva principalmente por meio de fatores internos às firmas, ou seja, uma visão de dentro para fora da organização (paradigma inside-out).

No segundo eixo, encontram-se outras duas teorias que estão associadas a uma visão dinâmica de mercado, enfatizando aspectos como desequilíbrio, descontinuidade e inovação, quais sejam, a Teoria de Processos de Mercado e a Teoria das Capacidades Dinâmicas. No contexto desta última abordagem, incluise a Teoria da Competição Baseada em Competências, a qual reconhece os níveis de incerteza envolvidos na mudança estratégica, assim como os processos cognitivos e a aprendizagem organizacional. Tal perspectiva constitui-se no foco desse trabalho.

Entende-se que diante de um cenário de negócios turbulento, com variações contínuas de tecnologia, produtos e mercado, no qual atuam fluxos globais, as abordagens tradicionais de estratégia, localizadas no primeiro eixo de análise da vantagem competitiva, apresentam limitações relevantes, uma vez que elas estão fundamentadas numa visão estratégica para estruturas industriais estáveis e identificáveis (Heene e Sanchez, 1997). Neste sentido, torna-se relevante analisar as teorias que consideram os aspectos de mudança e incerteza da concorrência. 
A partir de tais considerações, o objetivo do presente trabalho é aprofundar o exame da Teoria das Capacidades Dinâmicas, especificamente com relação à Teoria da Competição Baseada em Competências, procurando delinear uma abordagem integradora das correntes tradicionais do pensamento estratégico empresarial. Em linhas gerais, busca-se combinar a Teoria de Posicionamento Estratégico e a Teoria Baseada em Recursos, ambas componentes do primeiro eixo de análise, relacionando-se a uma visão estática da economia. A idéia central é associar os conceitos de criação de conhecimento e aprendizagem organizacional à conquista da vantagem competitiva sustentável.

Para tanto este trabalho divide-se em cinco seções, além desta introdução. A primeira seção mostra os paradigmas dominantes do campo da estratégia empresarial, principalmente da década de oitenta, que explicam a vantagem competitiva. A segunda seção apresenta a abordagem integradora da Competição Baseada em Competências. A terceira seção aborda outras questões cruciais para a Teoria da Competição Baseada em Competências, quais sejam a criação de conhecimento e a aprendizagem organizacional. Na quarta seção é apresentada uma proposta pedagógica para combinar a abordagem construtivista com a Teoria da Criação do Conhecimento, visando à consolidação da Teoria da Competição Baseada em Competências. Ainda nesta parte, são apresentados dados empíricos obtidos de uma experiência concreta que está sendo realizada atualmente no Banco do Brasil, a título de ilustração. Na quinta seção são apresentadas as considerações finais, incluindo determinadas questões que podem ser exploradas em pesquisas futuras.

\section{As Teorias Explicativas da Vantagem Competitiva: os Paradigmas Outside-IN e Inside-Out}

\section{Teoria da Organizaçăo Industrial}

Entre as teorias que dominam a literatura e a prática da administração estratégica, destaca-se primeiramente o trabalho de Porter (1989), intitulado Competitive Strategy, publicado em 1980. Tal estudo enfatiza o conteúdo das estratégias, que consiste na verificação empírica das relações entre as condições externas e as estratégias internas, procurando identificar os fatores responsáveis pelo sucesso ou fracasso das firmas em distintos contextos (Mintzberg, Ahlstrand e Lampel, 2000).

Segundo Foss (1996), o trabalho desenvolvido por Porter (1989) tem como fundamento o modelo da nova organização industrial, a qual estuda a lucratividade 
dos oligopólios, objetivando a implementação de políticas de regulamentação governamental antitrustes. De acordo com esse modelo, o desempenho das empresas em uma indústria depende do comportamento dos agentes econômicos com respeito a preços e custos. Por sua vez, este comportamento é determinado pela estrutura da indústria na qual as empresas se inserem.

Em essência, Porter (1989) utilizou o modelo de Mason e Bain (apud Barney e Hesterly, 1996) em outra perspectiva, ou seja, considerando o poder dos monopólios em favor das firmas na formulação de suas estratégias. Neste sentido, a estrutura da indústria determina o comportamento dos compradores e vendedores que, por sua vez, determina o desempenho das empresas. Em outras palavras, a posição da firma dentro da indústria é o determinante crucial do sucesso ou fracasso das empresas, implicando que a estratégia de negócios das empresas deve ter como base a estrutura de mercado na qual elas operam. Assim, a análise de Porter (1989) é fundamentalmente externa, baseada na estrutura da indústria.

De forma resumida, a noção de estratégia para Porter (1989) está relacionada com a noção de adaptação. A lógica do posicionamento da firma na indústria expressa uma adaptação externa, na qual a escolha da estratégia correta permite à firma adaptar-se à estrutura da indústria. Ademais, esta estratégia também deve ser internamente coerente, de forma que seja possível adequar os elementos internos da empresa à sua posição na indústria.

\section{Teoria Baseada em Recursos}

No final dos anos oitenta, diversos trabalhos na área de Administração Estratégica indicaram que as diferenças existentes entre os desempenhos das firmas dentro de uma mesma indústria, se mostravam expressivamente superiores as diferenças de desempenho entre indústrias, significando que os fatores internos às empresas exerceriam um impacto maior em comparação aos fatores externos, isto é, à estrutura da indústria (Carneiro, Cavalcanti e Silva, 1999).

Essas idéias, apresentadas como um contraponto da análise externa de Porter (1989), originaram uma nova corrente de pensamento estratégico, a Teoria Baseada em Recursos, que enfoca essencialmente as questões internas às organizações (Carneiro, Cavalcanti e Silva, 1999). De acordo com Mintzberg, Ahlstrand e Lampel (2000), a origem da Teoria Baseada em Recursos pode ser encontrada no trabalho de Penrose (1997), que analisou os processos de crescimento das firmas como caracterizados pelas oportunidades externas e internas, as quais são decorrentes do conjunto de recursos das firmas, apresentando, assim, uma perspectiva diferente da economia neoclássica. 
O estudo de Penrose (1997) enfatiza os limites e as possibilidades dos recursos internos das firmas, destacando que a procura constante das empresas pela maximização do emprego dos recursos causa os desequilíbrios das firmas e dos mercados, sendo que dessas imperfeições do mercado as empresas extraem suas vantagens competitivas. Assim, quando as empresas criam produtos únicos, elas desenvolvem capacidades únicas, habilidades gerenciais, ou ainda recursos. Estas capacidades estabelecem, necessariamente, limites para a expansão da empresa em determinado período de tempo. Com isso a autora antecipou vários conceitos da Teoria Baseada em Recursos, tais como as especificidades das empresas, a heterogeneidade dos recursos e a importância do conhecimento desses recursos e de seus possíveis empregos.

A partir do trabalho de Penrose (1997), Wernerfelt (1984) propôs analisar as empresas tomando como ponto de partida seus recursos, ao invés de enfocar seus produtos, o que permite abrir novas perspectivas para a estratégia empresarial. Somando-se a isto, Barney (apud Barney e Hesterly, 1996, p.133) também desenvolve as idéias de Penrose (1997), transformando a visão baseada em recursos em uma teoria completa, a qual está construída a partir de dois pressupostos básicos com respeito às capacidades e aos recursos da firma: "1) os recursos e as capacidades podem variar, de forma significativa, através das firmas (pressuposto da heterogeneidade da firma); e 2) estas diferenças podem ser estáveis (pressuposto da imobilidade de recursos)".

Diante do que foi exposto, pode-se afirmar que a Teoria Baseada em Recursos diverge tanto da Teoria Econômica Tradicional, já que nesta as diferenças entre as firmas são tratadas como acidentais e eliminadas pelo mecanismo de mercado, quanto da Teoria da Organização Industrial, que considera as diferenças de desempenho decorrentes de fatores externos e não atribuídas aos recursos. Assim, de acordo com Hamel (1994), para alcançar diferenças de desempenho, é essencial que as empresas sejam capazes de gerar valor e não somente possuir recursos distintos, implicando mudança na própria natureza da concorrência, uma vez que a competição entre recursos e competências é mais importante do que a concorrência entre produtos.

A principal conseqüência dos pressupostos da Teoria Baseada em Recursos é que a diferença de desempenho entre as empresas, ou melhor, a obtenção da vantagem competitiva, é explicada pela heterogeneidade de recursos. Isso significa que a fonte básica para a vantagem competitiva são os recursos e competências desenvolvidos e controlados pelas firmas, os quais são elementos escassos e valiosos, assim como de difícil e custosa imitação e substituição. Em outros termos, as imperfeições do mercado de recursos possibilitam a obtenção de desempenho acima da média do mercado, sendo os recursos essenciais para as empresas conquistarem vantagem competitiva. 


\section{Críticas às Teorias Outside-In e Inside-Out}

Conforme mostrado anteriormente, durante a década de oitenta, a perspectiva dominante no que tange à análise estratégica era a Teoria da Organização Industrial (sobretudo o modelo de Porter [1989]), orientada de fora para dentro das organizações, a qual enfatiza o conteúdo das estratégias. Este modelo teórico explica o sucesso competitivo das empresas a partir da estrutura da indústria, deixando um papel secundário aos processos intraorganizacionais (Carneiro, Cavalcanti e Silva, 1999).

Nesta abordagem, o caráter exógeno das forças ambientais no que diz respeito à determinação da dinâmica interna da empresa exige um esforço contínuo dela em termos de adaptação ex post. Além disso, esta abordagem está fundamentada em pressupostos de racionalidade próximos aos da economia neoclássica, levando a uma superestimação da capacidade dos estrategistas (Vasconcelos e Cyrino, 2000).

Como uma alternativa a esse modelo teórico centrado no ambiente externo, surgem vários estudos empíricos no final da década de oitenta, os quais constituem a Teoria Baseada em Recursos, orientada de dentro para fora das organizações, com ênfase nos processos por meio dos quais a vantagem competitiva é desenvolvida e sustentada.

Dado que a Teoria Baseada em Recursos considera os recursos e competências das firmas como a fonte da vantagem competitiva, ela atribui papel secundário ao ambiente na determinação da estratégia competitiva. Ademais, o exame da diferença de desempenho entre as firmas é focado na existência ou não de recursos discretos (individuais e estáticos) e em seus resultados quanto ao desempenho, o que evidencia uma metodologia de análise relacionada com as idéias da economia neoclássica (embora em termos menos expressivos), ou seja, relativamente estática e ex post (Vasconcelos e Cyrino, 2000).

Considerando as semelhanças entre as duas teorias, entende-se que ambas trabalham com pressupostos neoclássicos de comportamento econômico, racionalidade, estabilidade e previsibilidade dos mercados. Como conseqüência disso, Heene e Sanchez (1997) argumentam que a Teoria da Organização Industrial e a Teoria Baseada em Recursos podem ter alcançado um impasse epistemológico crítico. Para estes autores, em ambientes dinâmicos e marcados pela incerteza, a construção das duas teorias baseia-se numa abordagem positivista, o que leva a explicações teóricas ex post dos ambientes competitivos e dos recursos importantes estrategicamente. Todavia, nas suas formas tradicionais, as teorias mencionadas apresentam uma capacidade limitada para fazer avaliações ex ante de resultados competitivos. 
Em resumo, pode-se afirmar que as teorias tradicionais de estratégia não explicam de forma adequada a dinâmica dos ambientes competitivos, nos quais a maioria das organizações compete atualmente, bem como os desafios enfrentados pelos executivos, ao criar e gerir as capacidades organizacionais. Diante de tais lacunas, a partir do início da década de noventa, diversos trabalhos foram realizados com base em uma perspectiva de integração das Teorias da Organização Industrial e Baseada em Recursos com uma abordagem dinâmica, sistêmica, cognitiva e holística (Heene e Sanchez, 1997), objetivando construir uma nova teoria, fundamentada no conceito central de competência, a Competição Baseada em Competências. O próximo item aborda esta teoria.

\section{A Abordagem Integradora: Teoria da Competição Baseada EM COMPETÉNCIAS}

A Teoria da Competição Baseada em Competências tem a sua origem no conceito de competências essenciais de Prahalad e Hamel (1998, p.298), definidas por estes autores como "o aprendizado coletivo na organização, especialmente como coordenar as diversas habilidades de produção e integrar as múltiplas correntes de tecnologias". Partindo desse conceito de competências essenciais, a Teoria da Competição Baseada em Competências integra as duas perspectivas da teoria da estratégia descritas anteriormente, isto é, busca combinar a visão positivista, econômica, baseada em conteúdos e liderada por pesquisadores acadêmicos, tendo como referência a Teoria da Organização Industrial, com a perspectiva pragmática, liderada por praticantes (practioners), baseada em processos cognitivos e que tem como referência a Teoria Baseada em Recursos.

Dessa forma, o modelo para o gerenciamento estratégico incorpora e integra vários aspectos da teoria estratégica que antes eram tratados independentemente. Assim, a Teoria da Competição Baseada em Competências combina perspectivas sobre processos organizacionais com as perspectivas sobre dotações de recursos. A estrutura da indústria não é mais determinada exogenamente, sendo que a construção e alavancagem de competências das firmas conduzem a evolução da indústria. Como reflexo, o conhecimento gerencial e a capacidade de aprendizagem das organizações são considerados o motor da mudança estratégica, determinando as dotações de recursos das firmas individuais e a dotação de recursos coletivos que define a estrutura da indústria. As empresas competem por recursos críticos e por mercados de produto e, concomitantemente, cooperam para criar novos recursos e mercados.

Nesse contexto, o papel da cognição gerencial é reconhecido como essencial 
na Teoria da Competição Baseada em Competências, gerando diferenças nas capacidades das firmas. As competências são gerenciadas como um sistema e os objetivos estratégicos devem ser gerenciados holisticamente. No curto prazo, as alianças competitivas podem tornar-se um meio para obter oportunidades de mercado. Entretanto, no longo prazo, a sustentação da vantagem competitiva depende de uma capacidade superior para identificar, construir e alavancar novas competências. Desse modo, a aprendizagem se torna a variável estratégica crítica para o sucesso competitivo.

Comparativamente às Teorias da Organização Industrial e Baseada em Recursos, a Competição Baseada em Competências mostra-se mais completa, na medida em que analisa a competição como uma disputa dinâmica entre competências, isto é, entre firmas, buscando equilibrar duas realidades: (1) a dinâmica e a complexidade do mundo real; e (2) as capacidades cognitivas limitadas do homem diante de tal complexidade dinâmica (Heene e Sanchez, 1997).

\section{O Conceito Multidimensional de Competências}

Na abordagem teórica desenvolvida por Heene e Sanchez (1997), o conceito de competência refere-se à capacidade que uma organização possui para sustentar alocações coordenadas de recursos, a fim de ajudar a empresa a atingir os seus objetivos. De acordo com tal conceito, a empresa enfrenta dois tipos de decisões estratégicas: (1) a alavancagem de competências, o que significa que a empresa aloca os recursos sem que ocorram mudanças qualitativas nos ativos, capacidades e formas de coordenação dos recursos; e (2) a construção de competências, na qual as firmas adquirem e empregam ativos novos e diferentes em termos qualitativos, bem como capacidades e formas de coordenação de recursos. Ressalta-se que as competências que permeiam o referido modelo são encaradas como multidimensionais - dinâmicas, sistêmicas, holísticas e cognitivas caracterizando a complexidade e a dinamicidade do ambiente.

Em primeiro lugar, as competências são dinâmicas, pois a alavancagem de competências (competence leveraging) e a construção de competências (competence building) exigem a ocorrência de interação de pessoas e grupos dentro das empresas; de empresas e fornecedores externos de recursos; de firmas e clientes; de empresas competitivas e cooperativas.

Em segundo lugar, as competências também são sistêmicas, pois as firmas funcionam como sistemas abertos que visam a alcançar objetivos definidos, cujos ativos tangíveis e intangíveis interconectados são organizados sob uma lógica estratégica de realização de resultados, mediante o uso de vários processos gerenciais, incluindo a alavancagem e a construção de novas competências. 
Em terceiro lugar, as competências também são cognitivas, na medida em que assumem características de uma disputa entre conhecimentos gerenciais para identificar as competências importantes para a organização no futuro, tornandose o foco dos objetivos organizacionais de construção de competências. Dadas as diferenças de cognição gerencial, têm-se diferenças de padrões de construção de competências e atividades de alavancagem.

Finalmente, as competências são holísticas, uma vez que a Teoria da Competição Baseada em Competências propõe uma medida de desempenho da firma que vai além dos indicadores de retorno financeiro e rentabilidade, apresentando uma visão de empresa como sistema multidimensional, ao mesmo tempo quantitativo e qualitativo, tangível e intangível: humano, social e econômico. Conforme Heene e Sanchez (1997, p.21), "para que se possa compreender o processo de construção de competências é necessário uma visão das empresas como sistemas humanosociais e econômicos".

Diante do que foi apresentado, é importante destacar que a Teoria da Competição Baseada em Competências segue como referência o conhecimento gerencial e a capacidade de aprendizagem organizacional como o motor da mudança estratégica. Entretanto, embora a teoria destaque os papéis da aprendizagem e do conhecimento como o motor da mudança estratégica, ela não explora as questões de como a aprendizagem ocorre ou de como o conhecimento é criado e gerenciado. É nessa perspectiva que tais construtos serão discutidos na próxima seção.

\section{Aprendizagem Organizacional e Criação do Conhecimento}

O tema aprendizagem organizacional tem sido explorado de forma ampla nos contextos acadêmicos e empresariais. De acordo com Huysman (2001), podem ser identificadas quatro grandes tendências em tais contextos: (1) tendência à melhoria com foco em resultados (Argyris e Schön, 1978); (2) tendência à ação individual com ênfase na aprendizagem individual (Dodgson apud Huysman, 2001); (3) tendência à adaptação ambiental, destacando o alinhamento com o ambiente (Fiol e Lyles, 1985); e (4) tendência à aprendizagem planejada, enfocando as organizações de aprendizagem (Senge apud Huysman, 2001).

No escopo desse trabalho destaca-se a abordagem de Argyris e Schön (1978), segundo a qual a aprendizagem organizacional está relacionada à solução de problemas concretos no contexto das empresas. Nesta mesma direção, a aprendizagem organizacional é conceituada por Goodman e Darr (1998, p. 419) 
como "o processo pelo qual uma unidade adquire conhecimento de outra unidade da mesma organização". Estes autores destacam três aspectos essenciais que caracterizam a aprendizagem em nível organizacional: (1) a difusão das trocas, envolvendo problemas e soluções, bem como suas conseqüências em termos organizacionais; (2) a memória organizacional, onde são registradas estas trocas; e (3) os mecanismos de compartilhamento e atualização destas soluções.

Segundo o ponto de vista adotado neste trabalho, entende-se que ambas as abordagens se encontram alinhadas com a perspectiva de Heene e Sanchez (1997), que associam a construção e a alavancagem de competências diretamente à melhoria de desempenho organizacional. Entretanto é importante registrar a crítica feita por Huber (apud Prange, 2001, p.49) a respeito de determinados autores que "enfatizam as fontes de conhecimento e negligenciam os processos de geração de conhecimento, ou seja, a aprendizagem toda".

É nesse contexto que se insere a Teoria da Criação do Conhecimento, de Nonaka e Takeuchi (1997, p.6), apresentada no livro Criação do Conhecimento na Empresa, a qual objetiva "examinar [...] os mecanismos e processos pelos quais o conhecimento é criado", identificando na interação de duas formas de conhecimento (tácito e explícito) e sua ocorrência no nível do sujeito e do grupo a gênese do conhecimento organizacional. Segundo esta teoria, o conhecimento explícito é passível de transmissão sistemática por meio de linguagem formal, sendo relacionado a eventos e objetos, independente de contexto. Por outro lado, o conhecimento tácito é pessoal, estando associado a um contexto específico e difícil de ser formalizado ou comunicado, o qual representa o conhecimento produzido pela experiência de vida, incluindo elementos cognitivos e práticos.

A Teoria da Criação do Conhecimento (Nonaka e Takeuchi, 1997) considera quatro processos de conversão de conhecimento: socialização (tácito-tácito), externalização (tácito-explícito), combinação (explícito-explícito) e internalização (explícito-tácito). Primeiramente o conhecimento tácito é socializado, depois externalizado e combinado em novos caminhos para então ser internalizado, abrindo caminho para a geração permanente de inovações, o que, por sua vez, pode levar à conquista de vantagem competitiva sustentável.

Em suma, a criação (e não a gestão) do conhecimento seria um "processo interminável que se atualiza continuamente" (Nonaka e Takeuchi, 1997, p.101) de interação de conhecimento tácito e explícito, formando espirais do conhecimento através da organização. A partir de processos de "conversão social”, ou seja, de interações dinâmicas das pessoas, o conhecimento é criado e se expande em termos de qualidade e de quantidade através da organização, extrapolando "níveis e fronteiras interorganizacionais". 
Todavia o sucesso obtido pela divulgação do livro de Nonaka e Takeuchi (1997) no Ocidente não correspondeu à aplicação prática das proposições ali contidas, bem como ao desenvolvimento do modelo universal de gerência proposto. Uma das críticas mais comuns, que é até reconhecida por um dos próprios autores, refere-se à dificuldade de operacionalizar a teoria no ambiente ocidental (Garvin, 1993; Von Krogh, Ichijo e Nonaka, 2000). Na visão deste trabalho, os problemas desta teoria não são exclusivamente de natureza operacional. Acredita-se que o problema principal está relacionado à ausência de uma dimensão pedagógica necessária aos processos gerenciais de criação, disponibilidade e uso do conhecimento no contexto organizacional. Para eliminar esta lacuna, propõe-se articular a Teoria da Criação do Conhecimento a uma abordagem pedagógica, o construtivismo. Nesta direção, Sveiby (2001, p.345) enfatiza o vínculo existente entre a abordagem construtivista e o conhecimento na reconstrução, a partir da experiência, da capacidade para agir do indivíduo e da realidade:

“construindo sobre Polanyi (1958) e Wittengesntein (1995), Sveiby (1994, 1997) define conhecimento como uma capacidade para agir (que pode ou não ser consciente). A ênfase da definição é sobre o elemento ação: uma capacidade para agir pode somente ser mostrada na ação. Cada indivíduo tem que recriar sua própria capacidade para agir e a realidade por meio da experiência - uma visão que é similar ao construtivismo".

É relevante destacar que, em se considerando o contexto da educação de adultos, a abordagem construtivista terá como foco a sua vertente da Andragogia, o que será tratado no próximo item.

\section{Em Direção a uma Proposta Pedagógica Construtivista}

De acordo com a epistemologia construtivista, o conhecimento não é dado pelo meio físico e social, bem como não nasce com o indivíduo por meio da sua bagagem hereditária (Becker, 2001). Conforme Piaget (1976), o conhecimento é construído por meio de processos contínuos de equilibrações cognitivas, ou seja, construções de estados de equilíbrio dinâmicos, por meio de elaborações sucessivas de novas estruturas cognitivas. Estas estruturas, longe de representar um estado de inatividade ou de repouso, são caracterizadas por trocas constantes. Tal como argumentado por García e Fabregat (1998, p.92), "todo conhecimento suscita, na medida que resolve os problemas anteriores, novos problemas. Isso implica melhoria cognitiva, exigida por uma necessidade intrínseca de construção ou superação".

Neste contexto, o conhecimento é o resultado das experiências individuais com 
o mundo, sendo construído pelos aprendizes, quando estes resolvem problemas. Conforme Driscoll (1994), o conhecimento é construído por meio da interação do indivíduo com o meio social e físico, dependendo tanto das condições do meio quanto das condições do indivíduo. Ademais, o conhecimento é dinâmico, ou seja, está sempre sendo construído, quando os indivíduos acumulam mais informações e tentam transacionar com ambientes complexos.

Dessa maneira, o paradigma construtivista enfatiza o aprendiz, o qual é encorajado a investigar e reconhecer o papel da experiência na aprendizagem. Neste modelo, os aprendizes e professores interagem e o conhecimento é gerado por meio do diálogo. Assim, a aprendizagem ocorre a partir de um estímulo dado aos aprendizes, constituindo-se num processo de resolução de problemas. Dentro da abordagem construtivista, entra em cena a Andragogia, cuja preocupação central é com a educação para adultos. Segundo esta perspectiva, os adultos aprendem melhor, quando eles são ajudados a aprender e quando aprendem o que eles têm necessidade de aprender para progredir nos estágios da vida. Além disso, os adultos são os seus próprios melhores professores e melhores recursos para a aprendizagem (Knowles, 1984).

Nesta direção, combinando-se a perspectiva construtivista com a Teoria da Criação do Conhecimento, pode ser desenvolvida uma proposta pedagógica ${ }^{(1)}$ fundamentada nas seguintes linhas de ação: (1) enfatizar, nas atividades de aprendizagem, as construções cognitivas dos educandos, estabelecendo interações do meio com o sujeito; (2) instaurar a fala do aprendiz, para que se possa compreender o alcance e os limites de sua capacidade cognitiva; (3) transformar a avaliação em processo de aprendizagem, considerando-se os pontos de vista cognitivo, afetivo e ético; (4) tratar o erro como instrumento analítico e não como objeto de punição, tendo em vista a capacidade limitada do sujeito humano diante da infinita diversidade do mundo real; (5) colocar o educando em interação com a ciência, a arte e os valores, superando a repetição pela construção; (6) exercer rigor intelectual, por meio da formalização e da experimentação, evitando a linha do laisser-faire; (7) relativizar o ensino em função da aprendizagem, entendida como construção do conhecimento; (8) compreender que as estruturas cognitivas provêm da interação dinâmica do sujeito com a realidade, a qual é transformada pelo sujeito e ao mesmo tempo o transforma; (9) pensar conteúdo e processo como duas faces de uma mesma realidade cognitiva, evitando transformar a relação pedagógica em mera transmissão de conteúdo.

Em síntese, entende-se que a combinação da Teoria da Criação do Conhecimento com a abordagem construtivista, a qual resulta na proposta pedagógica referida anteriormente, pode ter papel significante para a consolidação da Teoria da Competição Baseada em Competências, revelando-se uma importante 
corrente teórica em fase de desenvolvimento no campo da estratégia empresarial. Isto é, considerando que a Competição Baseada em Competências constitui uma teoria nova, o gap existente em tal modelo, no que diz respeito a como a aprendizagem ocorre ou como o conhecimento é criado e gerenciado, abre espaço para diferentes autores explorarem esses assuntos.

Com o propósito de ilustração, será relatado, mais adiante neste trabalho, o Programa Gestão da Excelência - PGE ${ }^{(2)}$, que está sendo implementado no Banco do Brasil, tendo como foco a identificação e disseminação de práticas gerenciais de excelência. Construído com base em uma orientação construtivista, entendese que este programa apresenta coerência com a proposta pedagógica descrita neste trabalho. Entretanto, primeiramente será explicitada a metodologia utilizada para coleta e análise dos dados sobre a experiência do PGE.

\section{Programa Gestão da Excelência (PGE)}

\section{Metodologia}

A pesquisa foi realizada a partir de uma perspectiva epistemológica de orientação interpretativa, denominada Actor's Approach (Arbnor e Bjerke, 1997), que busca a compreensão do fenômeno pesquisado a partir do ponto de vista dos respondentes, vistos como atores críticos e reflexivos, que constroem a realidade a partir de suas intencionalidades e elaborações de significados. A unidade de análise utilizada foram as melhores práticas gerenciais, definidas por meio de uma linha de orientação construcionista, que enfatiza abordagens socialmente orientadas para a compreensão dos processos de aprendizagem e construção de conhecimento (Easterby-Smith, Crossan e Nicolini, 2000).

Os dados empíricos foram coletados por meio de uma abordagem multimétodos (Hoppen, Lapointe e Moreau, 1997) em três etapas distintas, combinando observação participante, análise de documentos e entrevistas semi-estruturadas.

A primeira etapa ocorreu na cidade de Brasília, DF, no mês de maio de 2002, com a presença de um dos autores da pesquisa e duração de uma semana. Nesta etapa, o pesquisador interagiu com uma equipe de cinco funcionários, responsáveis pela coordenação e execução do programa, com o objetivo de aprofundar conhecimentos sobre o PGE, enfatizando as suas duas principais fases: (1) a primeira, voltada para formação de educadores corporativos; (2) a segunda, voltada para a realização de oficinas gerenciais por todo o país, com o objetivo de disseminar a metodologia do PGE em toda a empresa, por meio do treinamento de gerentes. Ainda com relação a esta etapa, a pesquisa foi realizada principalmente por meio de observação participante, em que pesquisador e 
pesquisados discutiram e analisaram temas diversos, tais como conhecimento, aprendizagem organizacional, metodologias de gestão, decisões de adotar e de contribuir com conhecimento, construtivismo e andragogia, tendo como referência o conteúdo e a metodologia do programa em foco.

A segunda etapa da pesquisa correspondeu à análise dos documentos referentes ao PGE, sendo realizada pelos dois autores da pesquisa no período de maio a setembro de 2002. O objetivo desta etapa foi identificar a coerência do conteúdo e práticas da experiência realizada no Banco do Brasil, a partir das percepções dos coordenadores do PGE, com o conteúdo e práticas presentes na proposta pedagógica referida em item anterior deste trabalho.

A terceira etapa, também realizada no mês de setembro de 2002 na cidade de Brasília, efetuou-se durante o início de uma nova rodada do PGE, por meio de uma segunda observação participante combinada com a realização de entrevistas semi-estruturadas. Nesta terceira etapa estavam sendo realizadas novas oficinas gerenciais para a formação de um novo grupo de educadores corporativos. Durante os dois dias de realização da oficina, um dos autores da pesquisa pôde presenciar a realização das dinâmicas do PGE, bem como todas as atividades de identificação, seleção e apresentação das práticas gerenciais de excelência entre os participantes. Além disso, foram realizadas entrevistas semi-estruturadas com cinco superintendentes regionais do banco, atuais usuários do PGE e participantes da oficina. O objetivo das entrevistas foi conhecer as percepções dos funcionários sobre as experiências de identificação e disseminação das melhores práticas gerenciais viabilizadas pelo programa, buscando verificar a consistência destas percepções com a abordagem construtivista nele preconizada.

Com base em tais etapas, a experiência do Banco do Brasil, assim como a análise dos dados empíricos, serão expostas a seguir.

\section{A Experiência do Banco do Brasil}

O Programa Gestão da Excelência - PGE, que abrange unidades geograficamente distribuídas pelo país, pode ser dividido em dois momentos: validação e implementação (Banco do Brasil, 2001). O primeiro momento correspondeu à validação do programa, realizada no período de julho de $2000 \mathrm{a}$ setembro de 2001, e incluiu as seguintes atividades: (1) auto-avaliação das dependências via sistema de grande porte; (2) elaboração pelas dependências de seus respectivos planos de ação, com autonomia para o direcionamento das ações de melhoria; (3) elaboração de relatórios de gestão; (4) avaliação das dependências por uma banca examinadora para posterior emissão de um relatório de avaliação, que contenha pontos fortes e oportunidades de melhoria. O segundo momento, 
com o objetivo de capacitação, correspondeu à realização de programa de treinamento, denominado Oficina Gerencial - Gestão da Excelência, destinado a um público-alvo de 3.066 funcionários, incluindo executivos e gerentes do banco. $\mathrm{O}$ treinamento tinha como objetivo debater e disseminar as práticas de gestão adotadas nas dependências, visando à melhoria de desempenho da empresa em termos de resultados.

A capacitação realizou-se em todos os estados brasileiros mais o Distrito Federal (afora Acre, Amapá e Roraima), no período de setembro a dezembro de 2001, compreendendo quatro fases distintas, cada uma com objetivos específicos: (1) sincretismo - compartilhar as práticas de gestão relatadas pelos participantes; (2) análise - compreender a gestão baseada nos critérios de excelência do Prêmio Nacional da Qualidade - PNQ; (3) síntese - selecionar os melhores casos para o banco de práticas; (4) prática - responder pesquisa de percepção sobre práticas de gestão na Direção Geral em Brasília, nas Superintendências Estaduais e na própria agência.

A partir do programa de capacitação, foram selecionadas 500 melhores práticas de excelência, classificadas conforme os seguintes critérios de qualidade do PNQ: liderança, estratégia e planos, clientes e sociedade, informações e conhecimento, pessoas e processos.

Como resultado, foi construído um banco de dados, utilizando o software Access. Cada prática está incluída em uma página específica, com os seguintes registros: critério evidenciado, dependência onde ocorreu a prática, nome do administrador da dependência, período em que ocorreu a prática, resumo da prática e seu respectivo número de identificação.

Ressalta-se que todas essas práticas, identificadas pelos próprios treinandos, tendo como referência a realidade de trabalho de cada um, correspondem a soluções concretas para problemas reais de trabalho, implicando benefícios diversos, tanto para a empresa e funcionários, quanto para a comunidade.

Entre as melhores práticas identificadas, pode-se destacar: (1) sistemas automatizados de acompanhamento de metas; (2) técnicas para aperfeiçoar o atendimento telefônico aos clientes; (3) estratégias de disseminação e acompanhamento das informações; (4) mapeamento das competências dos funcionários; (5) pesquisas internas de opinião sobre bem-estar e qualidade de vida no trabalho; (6) sistemas de controle da qualidade de serviços terceirizados e de fornecedores; (7) mapas de controle de produtividade; (8) aperfeiçoamento de critérios para avaliação de desempenho; (9) folders com orientações para os clientes; (10) sistemas de triagem e gestão do fluxo de informações internas e externas; (11) planilha para conhecer e acompanhar a evolução dos negócios da 
dependência; (12) gestão compartilhada do processo de tomada de decisões; (13) capacitação dos contabilistas para confecção de cadastros de clientes; (14) racionalização dos processos de cadastro de clientes; (15) ferramentas para aperfeiçoamento dos processos internos.

A partir do que foi exposto, pode-se estabelecer um paralelo entre as quatro fases vivenciadas neste programa de treinamento com as linhas de ação que compõem a proposta pedagógica apresentada em item anterior deste trabalho. Por exemplo, o momento do sincretismo permite enfatizar, nas atividades de aprendizagem, as construções cognitivas dos educandos, estabelecendo interações do meio com o sujeito. Além disso, é durante o sincretismo que se instaura a fala do aprendiz, para que se possa compreender o alcance e os limites de sua capacidade cognitiva a partir de seus pontos de vista. O momento da análise, por sua vez, permite exercer certo rigor intelectual, evitando-se o laisser-faire, na medida em que são obedecidos os critérios de excelência do PNQ. O momento da síntese, que compreende a seleção das melhores práticas, permite ao treinando compreender que as estruturas cognitivas provêm da interação dinâmica do sujeito com a realidade. Finalmente, no momento da síntese, o treinando, ao responder à pesquisa de percepção sobre as suas práticas de gestão e, de outro lado, ao pensar conteúdo e processo como duas faces de uma mesma realidade cognitiva, evita transformar a relação pedagógica em mera transmissão de conteúdo.

Ainda sobre a experiência, entende-se que é possível estabelecer comparações com a abordagem multidimensional das competências. Em primeiro lugar, vale destacar a dimensão dinâmica das competências. De um lado, o próprio exercício de identificação e explicitação das melhores práticas de excelência pode ser percebido como ação de alavancagem de competências. Mesmo que não signifique a criação de novas competências, a possibilidade de disseminação de um conhecimento tácito já existente por toda a organização pode ser considerado um fator de alavancagem. De outro lado, a identificação e a disseminação de melhores práticas, por si sós, podem representar o desenvolvimento de nova competência: a competência de extrair, disseminar e utilizar conhecimento por toda a organização. Em segundo lugar, sobre a dimensão holística das competências, ressaltam-se os critérios de excelência do PNQ, tais como Pessoal, Processos e Liderança. Sobre a dimensão sistêmica, podem-se destacar os critérios Clientes e Sociedade e Estratégia e Planos. Por último, sobre a dimensão cognitiva, pode-se salientar o critério Informação e Conhecimento, além de todo o processo de transformação de conhecimento tácito em explícito, por meio da identificação das melhores práticas. Atualmente, estas práticas estão disponibilizadas em um portal corporativo (meio web) para todos os funcionários do banco.

No mês de novembro de 2002 foram realizadas novas oficinas para 515 gerentes, 
com a identificação de 500 novas práticas de excelência. Com respeito à continuidade do programa, existe a previsão, a partir do primeiro trimestre de 2003, da implementação do PGE para 1.500 agências do banco, abrangendo um contingente aproximado de 30.000 pessoas, mantidos os objetivos explicitados anteriormente, quais sejam, debater e disseminar as práticas de gestão adotadas nas dependências, visando à melhoria de desempenho da empresa.

Registre-se que esta é apenas uma experiência entre as várias iniciativas relacionadas a gestão do conhecimento que estão ocorrendo atualmente na empresa, pois "em qualquer ponto no tempo, e em qualquer parte de uma determinada organização, indivíduos e grupos podem estar engajados em vários e diferentes aspectos e processos de gestão do conhecimento" (Alavi e Leidner, 2001, p.123).

\section{Considerações Finais}

O presente trabalho procurou aprofundar a análise da nova Teoria da Competição Baseada em Competências, que emergiu no início dos anos noventa, com o propósito de integrar as Teorias da Organização Industrial e a Baseada em Recursos.

Constatou-se que os paradigmas outside-in e inside-out, os quais dominaram respectivamente o início e o final da década de oitenta, não explicam de forma adequada a dinâmica dos ambientes competitivos, sobretudo após os acontecimentos observados desde a década de noventa.

A nova abordagem integradora dos dois paradigmas, a Teoria da Competição Baseada em Competências (Heene e Sanchez, 1997), tem como fundamento o conceito central de competências, encaradas como multidimensionais: dinâmicas, cognitivas, sistêmicas e holísticas; como referência o conhecimento gerencial e a capacidade de aprendizagem organizacional como o motor da mudança estratégica. Embora esta abordagem combine várias perspectivas da teoria da estratégia, ainda permanecem lacunas referentes a questões essenciais, como a aprendizagem e a gestão do conhecimento. Aqui, entram em cena as contribuições da Teoria da Criação do Conhecimento e a abordagem construtivista, com enfoque na Andragogia, permitindo aprofundar o estudo destas questões. Desse modo, considera-se que estes temas podem ser aprofundados em pesquisas futuras, visando ao refinamento e à consolidação da Teoria da Competição Baseada em Competências. 
Neste sentido, os resultados, ainda que incipientes, da experiência do Banco do Brasil podem apontar para uma estratégia promissora. Entende-se que as práticas de excelência, apresentadas anteriormente, representam a explicitação de conhecimento tácito, para posterior disseminação pela empresa, como estratégia de gestão de conhecimento. Nesta perspectiva, considerando-se que a fonte de vantagem competitiva reside na aplicação do conhecimento pela organização, a identificação e a utilização das melhores práticas indicam que está sendo pavimentado o caminho para um desempenho organizacional superior.

\title{
NOTAS
}

\begin{abstract}
${ }^{1}$ A proposta pedagógica desenvolvida neste trabalho é adaptada diretamente do trabalho de Becker (2001) que, por sua vez, foi inspirado na obra de Piaget (1976).

${ }^{2}$ O Programa Gestão da Excelência - PGE é desenvolvido e gerenciado por uma equipe de funcionários do Banco do Brasil, lotados na Diretoria de Distribuição e Canais de Varejo, na cidade de Brasília, DF. O programa utiliza o modelo de gestão do Prêmio Nacional da Qualidade - PNQ (primeiros passos, 500 pontos). Em sua etapa de validação, o programa envolveu cerca de 106 agências (incluindo agências de todos os níveis, sendo 4 agências por Estado), 25 superintendências no país, além da Unidade Central de Distribuição - DF, abrangendo cerca de 3.000 funcionários.
\end{abstract}

\section{ReferénCias Bibliográficas}

ALAVI, M.;

LEIDNER, D.

Review: knowledge management and knowledge management systems - conceptual foundations and research issues. MIS Quarterly, v. 25, n. 1, p. 107-136, Mar. 2001.

ARBNOR, I.; BJERKE, B.

Methodology for creating business knowledge. London: Sage Publications, 1997.
ARGYRIS, C.;

SCHÖN, D. A.

Organizational learning: a theory of action perspective. Reading, MA: Addison-Wesley, 1978.

BANCO DO BRASIL.

Programa Gestão da Excelência - PGE. Brasília, Diretoria de Distribuição e Canais de Varejo, 2001. 
BARNEY, J. B.;

HESTERLY, W.

Organizational economics: understanding the relationship between organizations and economic analysis. In: CLEGG, $\mathrm{S}$. R.; HARDY, C.; NORD, W. R. Handbook of organization studies. London: Sage Publications, 1996.

BECKER, F.

Educação e construção do conhecimento. Porto Alegre: Artmed, 2001.

CARNEIRO, J. M. T.; CAVALCANTI, M. A. F. D.; SILVA, J. F. da.

Os determinantes da sustentabilidade da vantagem competitiva na visão resourcebased. In: ENCONTRO DA ANPAD, 23., 1999, Foz do Iguaçu. Anais... Foz do Iguaçu: ANPAD, 1999. 1 CD-ROM.

DRISCOLL, M.

Psychology of learning for instruction. Needham: Allyn and Bacon, 1994.

EASTERBY-SMITH, M.;

CROSSAN, M.;

NICOLINI, D.

Organizational learning: debates past, present and future. Journal of Management Studies, v. 37, n. 6, p. 783-796, Sept. 2000.
FIOL, C. M.;

LYLES, M. A.

Organizational learning. The Academy of Management Review, v. 10, n. 4, p. 803-813, 1985.

FOSS, N. J.

Research in strategy, economics, and Michael Porter. Journal of Management Studies, v. 33, n. 1, p. 1-24, 1996.

GARCIA, A.;

FABREGAT, A.

A construção humana através da equilibração de estruturas cognitivas: Jean Piaget. In: MingueT, P. A. (Org.). A construção do conhecimento na educação. Porto Alegre: Artmed, 1998.

GARVIN, D. A.

Building a learning organization. Harvard Business Review, v. 71, n. 4, p. 78-91, 1993.

GOODMAN, P. S.;

DARR, E. D.

Computer-aided systems and communities: mechanisms for organizational learning in distributed environment. MIS Quarterly, v. 22, n. 4, p. 417-440, Dec. 1998. 
HAMEL, G.

The concept of core competence. In: HAMEL, G.; HEENE, A. C o m p e t e n c e - b a s e d competition. Chichester: John Willey \& Sons, 1994.

HEENE, A.;

SANCHEZ, R.

Competence-based strategic management. Chichester: John Wiley \& Sons, 1997.

HOPPEN, N.;

LAPOINTE, L.;

MOREAU, E.

Um guia para a avaliação de artigos de pesquisa em sistemas de informação. REAd, v. 2, n. 3, 1997. Disponível em: <http:// read.adm.ufrgs.br/read03/artigo/ guia_a.htm> Acesso em: 28 ago. 2001.

HUYSMAN, M.

Contrabalançando tendenciosidades: uma revisão crítica da literatura sobre aprendizagem organizacional. In: EASTERBYSMITH, M. et al. Aprendizagem organizacional e organização de aprendizagem. São Paulo: Atlas, 2001.

KNOWLES, M.

The adult learner: a neglected species. Houston: Gulf Publishing, 1984.
MINTZBERG, H.;

AHLSTRAND, B.;

LAMPEL, J.

Safári de estratégia. Porto

Alegre: Bookman, 2000.

NONAKA, I.;

TAKEUCHI, $\mathrm{H}$.

Criação de conhecimento na empresa: como as empresas japonesas geram a dinâmica da inovação. Rio de Janeiro: Campus, 1997.

PENROSE, E.

The theory of the growth of the firm. In: FOSS, N. J. Resources, firms, and strategies: a reader in the resource-based perspective. Oxford: Oxford University Press, 1997.

PIAGET, J.

A equilibração das estruturas cognitivas. Rio de Janeiro: Zahar, 1976.

PORTER, M. E.

Vantagem competitiva: criando e sustentando um desempenho superior. Rio de Janeiro: Campus, 1989.

PRAHALAD, C. K.; HAMEL, G.

A competência essencial da corporação. In: MONTGOMERY, C.; PORTER, M. E. Estratégia: a busca da vantagem competitiva. Rio de Janeiro: Campus, 1998. 
PRANGE, C.

Aprendizagem organizacional: desesperadamente em busca de teorias? In: EASTERBY-SMITH, M. et al. Aprendizagem organizacional e organização de aprendizagem. São Paulo: Atlas, 2001.

SVEIBY, K. E.

A knowledge-based theory of the firm to guide in strategy formulation. Journal of Intellectual Capital, v 2, n. 4, p. 344-358, 2001. Disponível em: $<$ http://www.emerald-library.com/ $\mathrm{ft}>$ Acesso em: 20 jul. 2001.
VASCONCELOS, F. C.;

CYRINO, A. B.

Vantagem competitiva: os modelos teóricos atuais e a convergência entre estratégia e teoria organizacional. Revista de Administração de Empresas, v. 40, n. 1, p. 20-37, out./dez. 2000.

VON KROGH, G.;

ICHIJO, K.;

NONAKA, I.

Enabling knowledge creation.

New York: Oxford University

Press, 2000.

WERNERFELT, B.

A resource-based view of the firm. Strategic Management Journal, v. 5, n. 2, p. 171-180, 1984. 